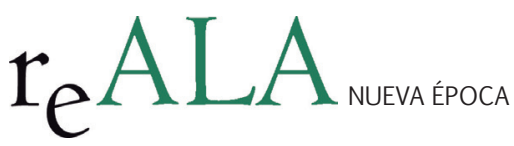

REALA, n 3, enero-junio 2015 ISSN: 1989-8975

DOI: http://dx.doi.org/10.24965/reala.voi3.10242

\title{
Una reflexión sobre los resultados obtenidos por la Administración local en el marco de la reforma del artículo 135 de la Constitución Española
}

\author{
Ángel Algarra Paredes \\ Doctor en Ciencias Económicas y Empresariales \\ Óscar Romera Jiménez \\ Doctor en Ciencias Económicas y Empresariales \\ oromera.jimenez@gmail.com
}

\section{Resumen}

Este artículo analiza el nuevo marco local tras la modificación del principio de estabilidad presupuestaria y la incorporación del principio de sostenibilidad financiera al máximo rango normativo. El nuevo escenario muestra a la Administración Local como referente dentro del conjunto de Administraciones bajo una propuesta dinámica, adaptable con incorporación de indicadores de medición y seguimiento, que detecten carencias y nuevos retos a incorporar a un modelo en evolución. Un marco cada vez más integrado en el proceso de transformación europea.

Palabras clave

Estabilidad presupuestaria, sostenibilidad financiera, indicadores económicos, economía de la información, resultados, control, evaluación, seguimiento.

\section{A reflection on the results obtained by the local administration in the context of the reform of Article 135 of the Spanish \\ Constitution}

Abstract

This article analyzes the new local frame after the modification of the principle of budgetary stability and the incorporation of the principle of financial sustainability to the maximum regulatory status. The new scenario shows the Local Administration as a reference within the set of government under a dynamic, customizable proposal incorporation of indicators for measuring and monitoring, to detect gaps and new challenges to incorporate and evolving model. A framework increasingly integrated in the process of European transformation.

Keywords

Budgetary stability, financial sustainability, economic indicators, information economy, results, check, review, tracing: 
Sumario

I.- Introducción. II.- La estabilidad presupuestaria y su relación con el artículo 135 de la Constitución Española. III.- El nuevo marco local y los resultados del cambio de modelo en el conjunto de las Administraciones Públicas. IV.- Conclusiones.

\section{I.- INTRODUCCIÓN}

La incorporación de cambios estructurales al modelo económico vigente que fomenten una mayor coordinación, vigilancia y estabilidad financiera para el conjunto de las Administraciones en el marco del compromiso de España con la Unión Europea, es un proceso que proyecta un conjunto de cambios orientados a transformar la Administración Pública española.

El principio de estabilidad presupuestaria avanza, en esta ocasión, como instrumento vinculado a la sostenibilidad financiera, que incorpora esa función rectora en la actuación económico-financiera de todas las Administraciones. Esta novedad no es coyuntural, sino que deberá contemplarse de una manera estructural.

Este escenario en el marco general del conjunto de las Administraciones provoca, de facto, una base mínima de homogeneización de las exigencias presupuestarias. Al mismo tiempo, consagra una conducta que necesariamente incorpora una visión integral de la Administración. Por otro lado, la diferenciación no deja de ser un principio deseable, necesario y profundamente enriquecedor. Si bien, debe ejercerse desde unos cimientos sólidos, realistas y sostenibles.

La confluencia en la implementación de elementos procedentes de la economía aplicada y aquellos otros basados en la economía de la información, no sólo debe generar y actualizar una sólida base de gestión capaz de incorporar los principios de estabilidad presupuestaria y sostenibilidad financiera elevados al máximo nivel normativo bajo la nueva redacción del artículo 135 de la Constitución Española. Además, es necesario incentivar de una manera proactiva una obligada dosis de transparencia. Al tiempo que se extiende el conocimiento de cara a la sociedad, de las bases de datos de información periódica y sensible con carácter público y obligatorio para el conjunto de la Administración española.

Este es el marco inspirador que se propone incorporar a la realidad del funcionamiento presente del conjunto de la Administración. Tan necesarios son los resultados en materia de consolidación fiscal como las reformas estructurales que incentivan la modernización de la Administración.

Si consideramos como elemento vital del modelo el principio de transparencia de la información, siempre dentro del proceso de consolidación fiscal, el deber de ofrecer a la sociedad la información sobre el grado de cumplimiento de los objetivos económicos perseguidos, se convierte en un hábito necesario a pesar del riesgo de tener que ofrecer explicaciones sobre su ritmo y nivel de realización.

La normalización y prevalencia de parámetros que incorporen criterios de eficiencia asignativa sobre aquellos otros que sólo buscan la productiva, identifica un mecanismo de valor añadido al modelo actual. Aquellos escenarios de gestión comparada sobre una base homogénea que garantice la prestación de servicios fundamentales, ofrecerán respuestas efectivas que ayudarán a consolidar la heterogeneidad, la diferenciación y la sostenibilidad como pilares básicos de un sistema que transparenta los recursos que tiene y genera un flujo de información bidireccional que incorpora un conocimiento más exacto no sólo entre lo disponible y lo deseable. Además, ofrece nuevas demandas en forma de nuevos retos a alcanzar. Un ciudadano más informado, dentro de una gestión más orientada a resultados bajo los principios de estabilidad presupuestaria y sostenibilidad financiera y, sobre una base homogénea de servicios comparables fomenta una responsabilidad sostenible en el tratamiento de estructuras heterogéneas como respuesta a las demandas ciudadanas.

Por otro lado, dentro de esos nuevos retos, se pueden identificar al menos tres que serán fundamentales para asentar los valores que incorpora todo el desarrollo normativo implementado en fechas recientes. Al menos desde un punto de vista local, en primer lugar, a la reforma competencial debe añadirse una actualización del sistema de financiación y a la vista de los resultados obtenidos en los diferentes ámbitos territoriales la solución será compleja y no exenta de debate. Mientras esa actuación llega, un segundo paso sería la evaluación del impacto de la nueva normativa en el sector público empresarial local, aún por comprobar. Finalmente, el análisis sobre el impacto del denominado techo de gasto, amparado en garantizar la viabilidad y consolidación de estructuras superavitarias, pero exento de una alternativa real, al día de la fecha, para invertir parte de los recursos generados cuando se alcanzan posiciones de solvencia económico-financiera conforman los tres ejes iniciales de valoración y revisión. En este sentido, serán desarrollados por su interés en sucesivos trabajos. 
Finalmente, la senda marcada por la consecución de objetivos en materia de política económica y fiscal comprometidos con nuestros socios europeos. Y por ende, en términos de crecimiento económico y generación de empleo, viene a justificar de manera amplia, a nuestro criterio, el nuevo marco habilitado como veremos a continuación.

\section{II.- LA ESTABILIDAD PRESUPUESTARIA Y SU RELACIÓN CON EL ARTÍCULO 135 DE LA CONSTITUCIÓN ESPAÑOLA}

El principio de estabilidad presupuestaria constituyó una novedad en el año 2001, tras la aprobación de la Ley 18/2001, de 12 de noviembre, de estabilidad presupuestaria y la Ley Orgánica 5/2001, de 13 de diciembre, conforme al Pacto de Estabilidad y Crecimiento acordado en junio de 1997. De facto, se incorpora una limitación del uso del déficit público y de su contención de una forma armonizada para el conjunto de los países que constituyen la Unión Económica y Bancaria. En España, para garantizar tal fin, se hizo uso de la competencia exclusiva del Estado según los artículos $149 \cdot 1 \cdot 11^{\mathrm{a}}$ y $14^{\mathrm{a}}$ y $149 \cdot 1 \cdot 13^{\mathrm{a}}$ y $18^{\mathrm{a}}$ de la $\mathrm{CE}^{1}$.

Tras explicitar este compromiso y elevarlo a principio rector dentro del funcionamiento de la Administración española, el contenido de las leyes 18/2001, de 12 de noviembre y la LO 5/2001, de 13 de diciembre se vio modificado sustancialmente por la LO 3/2006 y por la Ley 15/2006 lo que generó un nuevo Texto Refundido de la Ley de Estabilidad Presupuestaria, aprobado por RDL 2/2007, de 28 de diciembre.

La necesidad de controlar los crecientes déficits públicos de las Administraciones españolas vuelve a posibilitar una interpretación más restrictiva de dicho principio. Tras una etapa de flexibilización, que trajo consigo que en el año 2006 se adoptaran nuevas normas vinculadas al Pacto de Estabilidad y Crecimiento.

En este sentido, se establecía una interpretación más laxa del concepto de déficit estructural y cíclico. No tardaron en surgir motivos suficientes para incluir nuevas exigencias en la definición de la estabilidad presupuestaria como respuesta a la más que justificada preocupación por la consecución del equilibrio de las cuentas públicas.

En este caso, la solución habilitada en la reforma del artículo 135 de la CE tiene su reflejo en otras propuestas de similar resolución realizadas en otros Estados fuertemente descentralizados, como el alemán (ver tablas 1 y 2 ). En septiembre de 2011², se aprueba la reforma del nuevo artículo 135 de la Constitución Española (CE).

TABLA 1. GASTO PÚBLICO CONSOLIDADO DE CADA NIVEL DE GOBIERNO (PORCENTAJE DE GASTO PÚBLICO TOTAL). AÑO 2011

\begin{tabular}{|c|c|c|c|c|}
\hline \multirow[b]{2}{*}{ PAÍSES } & \multirow{2}{*}{$\begin{array}{c}\text { CENTRAL } \\
(\%)\end{array}$} & \multicolumn{3}{|c|}{ SUBCENTRALES } \\
\hline & & $\begin{array}{c}\text { INTERMEDIO } \\
(\%)\end{array}$ & $\begin{array}{c}\text { LOCAL } \\
(\%)\end{array}$ & $\begin{array}{c}\text { TOTAL } \\
(\%)\end{array}$ \\
\hline ALEMANIA & 61,30 & 22,25 & 16,46 & 38,70 \\
\hline ESPAÑA & 53,69 & 34,11 & 12,20 & 46,31 \\
\hline BÉLGICA & 63,16 & 23,77 & 13,07 & 36,84 \\
\hline DINAMARCA & 37,18 & - & 62,82 & 62,82 \\
\hline SUECIA & 51,29 & 一 & 48,71 & 48,71 \\
\hline SUIZA & 42,89 & 36,61 & 20,49 & 57,10 \\
\hline FRANCIA & 79,53 & - & 20,47 & 20,47 \\
\hline GRECIA & 94,24 & 一 & 15,76 & 15,76 \\
\hline IRLANDA & 88,03 & 一 & 11,97 & 11,97 \\
\hline PORTUGAL & 85,94 & - & 14,06 & 14,06 \\
\hline
\end{tabular}

Fuente: OCDE y FMI.

1 Peña Velasco, Gaspar. Deuda pública y ley de presupuestos / Gaspar de la Peña Velasco., en Las Cortes Generales / [organizadas por la] Dirección General del Servicio Jurídico del Estado. -- Madrid : Instituto de Estudios Fiscales, D.L. 1987. -- Vol. III (p. 1907-1933).

2 http://www.congreso.es/consti/constitucion/indice/sinopsis/sinopsis.jsp?art=135\&tipo=2 
TABLA 2. INGRESOS FISCALES CONSOLIDADOS DE CADA NIVEL DE GOBIERNO (PORCENTAJE DEL TOTAL DE INGRESOS FISCALES). AÑO 2011

\begin{tabular}{|l|c|c|c|c|}
\hline \multirow{2}{*}{\multicolumn{1}{c|}{ PAÍSES }} & \multirow{2}{*}{$\begin{array}{c}\text { CENTRAL } \\
\text { (\%) }\end{array}$} & & \multicolumn{3}{c|}{ SUBCENTRALES } \\
\cline { 5 - 6 } & & INTERMEDIO & $\begin{array}{c}\text { LOCAL } \\
(\%)\end{array}$ & $\begin{array}{c}\text { TOTAL } \\
(\%)\end{array}$ \\
\hline ALEMANIA & 70,63 & 21,31 & 18,06 & 29,37 \\
\hline ESPAÑA & 67,44 & 23,11 & 19,45 & 32,56 \\
\hline BÉLGICA & 89,53 & 15,32 & 15,14 & 10,46 \\
\hline DINAMARCA & 73,11 & - & 26,89 & 26,89 \\
\hline SUECIA & 64,32 & - & 35,68 & 35,68 \\
\hline SUIZA & 60,63 & 24,07 & 15,29 & 39,36 \\
\hline FRANCIA & 86,89 & - & 13,11 & 13,11 \\
\hline GRECIA & 99,20 & - & 10,80 & 0,80 \\
\hline IRLANDA (2010) & 96,85 & & 13,15 & 3,15 \\
\hline PORTUGAL(2010) & 94,28 & & 15,72 & 5,72 \\
\hline
\end{tabular}

Fuente: OCDE y FMI.

En el marco local, a comienzos de 2011, la situación de la mayoría de los ayuntamientos españoles venía caracterizada por caídas en la recaudación, fundamentalmente provocadas por la desaparición de ingresos de carácter extraordinario procedentes del sector inmobiliario, que si bien favorecieron la expansión del gasto, también se constituyeron como una parte importante de esa fuente de recursos que sustentaban los gastos de inversión. No en vano, se consolidaron unas bases de gasto estructural que posteriormente tuvieron que corregirse (ver tabla 3) y que en algún supuesto, se vieron ampliadas por un excesivo recurso al endeudamiento. La consecuencia más inmediata tiene su traslación en la dispar elasticidad que presenta el origen del gasto frente al ingreso.

Los impactos en la gestión del modelo anterior afloran en las entidades locales, a modo de falta de liquidez, retrasos en el pago a proveedores, la acumulación déficits presupuestarios y sucesión de remanentes negativos de tesorería. La agenda diaria de la gestión económico-financiera se complica.

TABLA 3. EVOLUCIÓN DE LA PLANTA MUNICIPAL ESPAÑOLA (PERIODO 1993-2013).

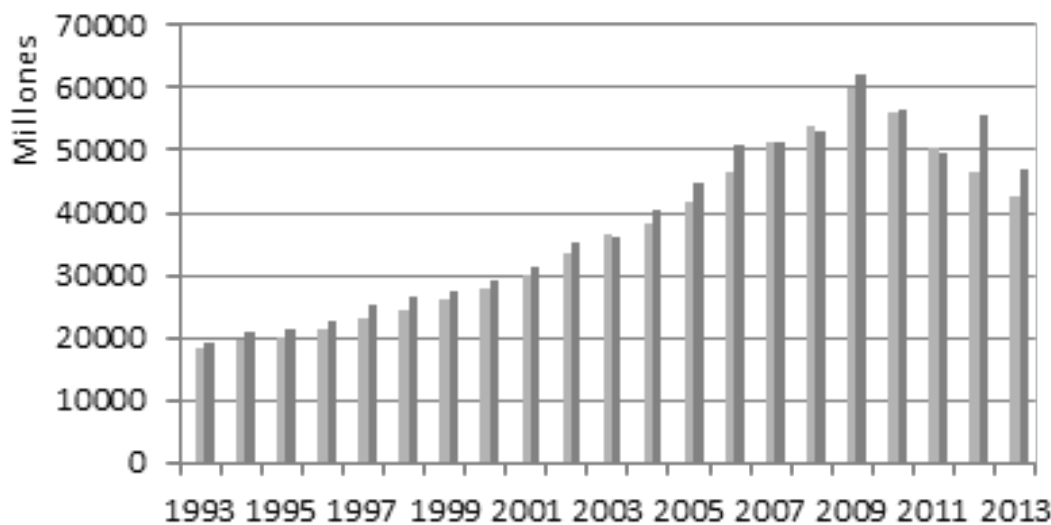

GASTOS (obligaciones reconocidas netas)

INGRESO (derechos reconocidos netos)

Fuente: elaboración propia a partir de datos de las liquidaciones presupuestarias (MINHAP)

En términos de proyección de imagen externa, existe una creciente preocupación por parte de nuestros socios europeos que añade aún más presión hacia la toma de decisiones que corrijan los crecientes desequilibrios que genera la economía española. El camino hacia la incorporación de los principios de estabilidad presupuestaria 
y sostenibilidad financiera al máximo rango normativo, a finales de 2011, es la consecuencia más evidente de esa necesidad de reacción.

Consecuencia de lo anterior, se desarrolla la Ley Orgánica 2/2012, de 27 de abril de Estabilidad Presupuestaria y Sostenibilidad Financiera. Como recoge su preámbulo "la crisis económica puso rápidamente de manifiesto la insuficiencia de los mecanismos de disciplina de la anterior Ley de Estabilidad Presupuestaria”. Quizás, lo más grave es la constatación de un déficit del 11,2\% del Producto Interior Bruto (en adelante, P.I.B), en 2009.

Las tensiones financieras de los mercados europeos, las dudas sobre el proyecto de integración de la Unión Europea y la necesidad de conseguir una mayor coordinación de las políticas europeas en materia fiscal y presupuestaria fueron argumentos adicionales para generar la tramitación de la norma. La actitud de no gastar más de lo que se ingresa y pagar lo que se debe en tiempo y forma, por lo tanto, no surge de la casualidad. Es bajo este nuevo marco, desde donde se asienta el impulso al crecimiento económico y la creación de empleo en la economía española.

En la remisión del artículo 135 de la Constitución Española, a la posterior LO 2/2012, de 27 de abril, se desarrolla el esquema que viene a asegurar la incorporación de los principios de estabilidad presupuestaria y sostenibilidad financiera al conjunto de las Administraciones Públicas.

La novedad que introduce el artículo 135 consiste en vincular el volumen total de deuda pública de todas las Administraciones Públicas a un valor de referencia que incorpora el artículo 126 del Tratado de Funcionamiento de la Unión Europea, que lo fija en un $60 \%$ del PIB. Además, los límites de déficit estructural y volumen de deuda se vinculan a los principios de responsabilidad, lealtad institucional y eficiencia ${ }^{3}$. El escenario se completa con el principio de sostenibilidad financiera. Su definición, como la capacidad para financiar compromisos de gasto presentes y futuros dentro de los límites de déficit, deuda pública y no superación del plazo máximo del periodo medio de pago a proveedores, genera un nuevo "hábito" a extender para el conjunto de las Administración española.

La evolución de los resultados consolidados obtenidos por la Administración Pública española (consultar tabla 4) viene a demostrar el nivel de compromiso de la Administración territorial con los objetivos de reducción de déficit excesivo.

TABLA 4. CAPACIDAD / NECESIDAD DE FINANCIACIÓN (\% PIB) A EFECTOS DE CUMPLIMIENTO DEL OBJETIVO DE DÉFICIT.

\begin{tabular}{|c|c|c|c|c|c|c|}
\hline CONCEPTO & $2011 *$ & 2012 & $2013(A)$ & $\begin{array}{c}2013 \\
\text { Objetivo }\end{array}$ & $\begin{array}{c}2013 \\
\text { Cierre } \\
\text { (SEC 2010) } \\
\end{array}$ & $\begin{array}{c}2014 \\
\text { Objetivo }\end{array}$ \\
\hline $\begin{array}{l}\text { Administraciones } \\
\text { Centrales sin ayuda } \\
\text { financiera: }\end{array}$ & $-5,27$ & $-5,20$ & $-5,49$ & $-5,20$ & $-5,33$ & $-3,5$ \\
\hline Estado + OOAA & $-5,20$ & $-4,21$ & $-4,33$ & $-3,80$ & & \\
\hline Seguridad Social & $-0,07$ & $-0,99$ & $-1,16$ & $-1,40$ & & \\
\hline $\begin{array}{l}\text { Sistema Seguridad } \\
\text { Social }\end{array}$ & $-0,22$ & $-0,87$ & $-1,19$ & & & \\
\hline SPEE & 0,23 & $-0,03$ & 0,11 & & & \\
\hline FOGASA & $-0,09$ & $-0,09$ & $-0,08$ & & & \\
\hline $\begin{array}{l}\text { Comunidades } \\
\text { Autónomas }\end{array}$ & $-3,41$ & $-1,86$ & $-1,54$ & $-1,30$ & $-1,52$ & $-1,0$ \\
\hline Corporaciones Locales & $-0,39$ & 0,22 & 0,41 & 0,00 & 0,52 & 0,00 \\
\hline $\begin{array}{l}\text { TOTAL AA.PP. Sin } \\
\text { ayuda financiera }\end{array}$ & $-9,07$ & $-6,84$ & $-6,62$ & $-6,50$ & $-6,33$ & $-5,5$ \\
\hline Ayuda financiera & 0,49 & 3,80 & 0,46 & & & \\
\hline $\begin{array}{l}\text { TOTAL AA.PP con } \\
\text { ayuda financiera }\end{array}$ & $-9,56$ & $-10,63$ & $-7,08$ & & & \\
\hline
\end{tabular}

Fuente: IGAE y Plan Presupuestario 2015. (A) Avance

3 Tanto en la asignación como en la utilización de recursos públicos dentro de un periodo transitorio de aplicación a partir de 2020. 
La senda auspiciada bajo los principios de estabilidad presupuestaria y sostenibilidad financiera busca alcanzar los objetivos que persiguen las nuevas pautas de comportamiento fijadas para la Administración en materia de política económica y fiscal.

La corrección del déficit del conjunto de las Administraciones ha sido de 2,57 puntos del P.I.B. en tan sólo tres ejercicios presupuestarios (2011/2013) en un contexto de recesión económica (2011/2012) bajo medidas de consolidación fiscal no exentas de perceptibilidad ciudadana.

\section{III.- EL NUEVO MARCO LOCAL Y LOS RESULTADOS DEL CAMBIO DE MODELO EN EL CONJUNTO DE LAS ADMINISTRACIONES PÚBLICAS}

La extensión de los efectos de los principios de estabilidad presupuestaria y sostenibilidad financiera operan en su vertiente local a través de la Ley $27 / 2013$, en adelante LRSAL, de racionalización y sostenibilidad de la Administración Local. Tras la nueva redacción del artículo 135 de la CE y su desarrollo a través de la LO 2/2012, llega su traslado efectivo a la Administración local a través de la actualización de la Ley 7/1985, de 2 de abril, Reguladora de las Bases del Régimen Local.

El despliegue y la evidente conexión normativa, extiende sus efectos al conjunto de la Administración local. Los escenarios que se proyectan fomentan la medición del gasto, su evaluación y la toma de decisiones dentro de un deber coordinado. El ejercicio se realiza por la vía del ajuste competencial.

Las comprobaciones auspiciadas bajo los nuevos parámetros fijados, vienen a refrendar de una manera definitiva la estrecha vinculación existente entre los desarrollos normativos.

La existencia de una trazabilidad que parte de la Constitución Española no ofrece lugar a dudas. Los indicadores para el cambio muestran su relación directa y fortalecen los mecanismos de anclaje del sistema.

La estabilidad presupuestaria (Ley Orgánica 2/2012, de 27 de abril, de Estabilidad Presupuestaria y Sostenibilidad Financiera-en adelante, LOEPSF- y la Ley 27/2013, de 27 de diciembre, de racionalización y sostenibilidad de la Administración Local-en adelante, LRSAL-), el objetivo de deuda (LOEPSF, la actualización del Real Decreto Legislativo 2/2004, de 5 de marzo, por el que se aprueba el texto refundido de la Ley Reguladora de las Haciendas Locales y la LRSAL), la regla de gasto (LOEPSF y LRSAL), el periodo medio de pago (LOEPSF, la Ley Orgánica 9/2013, de 20 de diciembre, de control de la deuda comercial en el sector público y la LRSAL) y la sostenibilidad financiera (LOEPSF y LRSAL) promueven un comportamiento económico-financiero convergente para el conjunto de las Administraciones.

La evaluación, su seguimiento y los efectos del incumplimiento de los parámetros relacionados en el párrafo anterior (ver tabla 15) nos ofrece un ejemplo de cómo se habilita un cauce muy preciso que viene a asegurar el cumplimiento de la normativa vigente en términos de elaboración del correspondiente Plan económico financiero (adopción efectiva de medidas aprobadas; informe trimestral de seguimiento con publicidad; elevación de informe a CNAL; aplicación de medidas coercitivas).

No obstante, el mecanismo no finaliza aquí. Su incidencia se fortalece mediante elementos adicionales que alertan y retroalimentan las hipotéticas debilidades que pudiese presentar el modelo. Así, ante un posible desajuste por acumulación del gasto, en el ámbito local, procedente de aquellas competencias distintas a las obligatorias o atribuidas por delegación -las comúnmente denominadas impropias-, se puede concluir de manera preliminar la inexistencia de un detector que aflore esa disfunción de consecuencias directas para la gestión económicofinanciera de la entidad local. Y no nos estamos refiriendo a los dos informes preceptivos y vinculantes del artículo 7.4 de la Ley 27/2013 (LRSAL) en términos de no duplicidad y sostenibilidad de la hacienda local. Vamos más allá, al observar un comportamiento claramente “en rebeldía” al mandato considerado por la norma.

Dicho lo anterior, en el hipotético “desbordamiento” de la LRSAL, por la vía de los hechos, no se considera ningún detector ni sanción al objeto de paliar esa injustificable conducta. Es más, una corporación podría acumular este tipo de gasto de manera voluntaria y autónoma siempre y cuando conservara la estabilidad presupuestaria sin constatarse, en principio, alerta alguna. Nos encontraríamos ante un fallo del sistema. Y por lo tanto, ante una "amenaza" para el proceso que se quiere implantar contenido en la LRSAL.

La ventana de oportunidad para aquellos gestores que no comparten los nuevos criterios de estabilidad y sostenibilidad se convertiría en un hecho.

La prueba evidente de la coordinación normativa, la encontramos en la solución a este planteamiento. Sólo hace falta ir a la misma LRSAL en su relación con la LOEPSF para encontrar una respuesta.

En este sentido, la aplicación del artículo 116 bis de la LRSAL sobre el contenido y seguimiento de un plan económico-financiero habilitado bajo el artículo 21 de la LOEPSF anularía el efecto y ajustaría el modelo al facilitar 
un mecanismo de cierre por el que la entidad local vería penalizado ese comportamiento no comunicado a la Administración competente con consecuencias directas para el ciudadano. Y además, forzaría al gestor a dar explicaciones de su gestión. Por lo tanto, la conectividad de la LRSAL con la LOEPSF amplía sus efectos cuando se añade la obligación de transparentar los motivos de una mala gestión. En este caso, al objeto de eliminar un exceso de gasto no obligatorio desarrollado bajo el artículo 7.4, nos ofrecería un conjunto de decisiones que tienen una repercusión directa en el día a día del ciudadano (supresión de competencias distintas de las propias y de las ejercidas por delegación; gestión integrada o coordinada de servicios obligatorios para reducir costes; incremento de ingresos para financiar esos servicios obligatorios; racionalización organizativa; supresión de entidades locales menores si incumplen los parámetros de gestión ordinaria -estabilidad presupuestaria, objetivo de deuda pública o superación del periodo medio legal de pago a proveedores en más de treinta días; o fusión con municipio colindante).

Por lo tanto, el fallo preliminar detectado en la LRSAL quedaría solucionado gracias a la relación directa y bidireccional que tiene con la LOEPSF. Y todo lo anterior, bajo la influencia de la nueva redacción de la Constitución Española.

Al margen del debate anterior, dentro de un contenido más jurídico, enfoquemos el impacto de la nueva redacción del artículo 135 desde una perspectiva más económica.

La evolución de la Administración Local bajo los principios rectores de estabilidad y sostenibilidad viene acompañada por diversas medidas de orden económico, tributario y administrativo que ofrecen una corrección del déficit del subsector de las Corporaciones Locales del -0,39\% (2011) al 0,52\% (2013). Su cuantificación se eleva a los 4.247,2 millones de euros, tal como puede verse en las tablas 5, 6 y 7.

El esfuerzo realizado por la Administración local se refleja en un 6,09\% menos del gasto que se realizaba en el ejercicio 2011. Al mismo tiempo, se consolidan unos ingresos en 2013 superiores en un $2,96 \%$ a los del año 2011 , con 2.038 millones de euros más.

En términos agregados, esa diferencia en la elasticidad a la que nos referíamos a la hora de confrontar la toma de decisión del ingreso frente al gasto, se traduce en que el esfuerzo realizado por la Administración Local, procede en 3 de cada 10 euros por la vía del ingreso, frente a los 7 restantes generados por el lado del gasto.

TABLA 5. CLASIFICACIÓN ECONÓMICA CONSOLIDADA Y EJECUCIÓN DEL TOTAL DE ENTIDADES LOCALES (TOTAL NACIONAL). INGRESO

\begin{tabular}{|c|c|c|c|c|c|c|c|c|c|c|}
\hline CAp. & Ingresos & $\begin{array}{c}\text { Derechos } \\
\text { Reconocidos } \\
\text { Netos (D.R.N) } \\
\text { (Avance 2013) }\end{array}$ & $\begin{array}{l}\text { D.R.N. } \\
\text { (2012) }\end{array}$ & $\begin{array}{l}\text { D.R.N. } \\
\text { (2011) }\end{array}$ & DIF $13-12$ & $\%$ & DIF 12-11 & $\%$ & DIF 13-11 & $\%$ \\
\hline 1 & Impuestos directos & 26.846 .027 & 24.892 .213 & 23.557 .340 & 1.953 .814 & $7,85 \%$ & 1.334 .872 & $5,67 \%$ & 3.288 .686 & $13,96 \%$ \\
\hline 2 & Impuestos indirectos & 8.212 .214 & 7.864 .291 & 7.998 .682 & 347.923 & $4,42 \%$ & $-134 \cdot 391$ & $-1,68 \%$ & 213.532 & $2,67 \%$ \\
\hline 3 & $\begin{array}{l}\text { Tasas, precios públicos } \\
\text { y otros ingresos }\end{array}$ & 10.390 .616 & 10.257 .192 & 10.081 .112 & 133.424 & $1,30 \%$ & 176.081 & $1,75 \%$ & 309.504 & $3,07 \%$ \\
\hline 4 & $\begin{array}{l}\text { Transferencias } \\
\text { corrientes }\end{array}$ & 19.544 .439 & 18.597 .954 & 19.052 .577 & 946.485 & $5,09 \%$ & -454.623 & $-2,39 \%$ & 491.862 & $2,58 \%$ \\
\hline 5 & Ingresos patrimoniales & 1.262 .822 & 1.225 .139 & 1.448 .868 & 37.683 & $3,08 \%$ & -223.729 & $-15,44 \%$ & -186.046 & $-12,84 \%$ \\
\hline & Operaciones Corrientes & 66.256 .117 & 62.836 .788 & 62.138 .579 & 3.419 .329 & $5,44 \%$ & 698.210 & $1,12 \%$ & 4.117 .538 & $6,63 \%$ \\
\hline 6 & $\begin{array}{l}\text { Enajenación inversiones } \\
\text { reales }\end{array}$ & 286.452 & 399.183 & 530.905 & -112.731 & $-28,24 \%$ & -131.722 & $-24,81 \%$ & -244.453 & $-46,04 \%$ \\
\hline 7 & $\begin{array}{l}\text { Transferencias de } \\
\text { capital }\end{array}$ & 1.378 .923 & 1.670 .047 & 3.179 .651 & -291.123 & $-17,43 \%$ & -1.509 .604 & $-47,48 \%$ & -1.800 .728 & $-56,63 \%$ \\
\hline & Operaciones de Capital & $1.665 \cdot 375$ & 2.069 .229 & 3.710 .555 & -403.854 & $-19,52 \%$ & -1.641 .326 & $-44,23 \%$ & -2.045 .181 & $-55,12 \%$ \\
\hline & $\begin{array}{l}\text { Operaciones no } \\
\text { Financieras }\end{array}$ & 67.921 .492 & 64.906 .018 & 65.849 .134 & 3.015 .475 & $4,65 \%$ & -943.117 & $-1,43 \%$ & 2.072 .358 & $3,15 \%$ \\
\hline 8 & Activos financieros & 307.883 & 455.661 & 262.555 & -147.778 & $-32,43 \%$ & 193.106 & $73,55 \%$ & 45.328 & $17,26 \%$ \\
\hline 9 & Pasivos financieros & 2.711 .105 & 9.995 .265 & 2.790 .018 & -7.284 .161 & $-72,88 \%$ & 7.205 .247 & $258,25 \%$ & -78.914 & $-2,83 \%$ \\
\hline & $\begin{array}{l}\text { Operaciones } \\
\text { Financieras }\end{array}$ & 3.018 .988 & 10.450 .926 & 3.052 .574 & -7.431 .939 & $-71,11 \%$ & 7.398 .353 & $242,36 \%$ & -33.586 & $-1,10 \%$ \\
\hline & Total ingresos & 70.940 .480 & 75.356 .944 & 68.901 .708 & -4.416 .464 & $-5,86 \%$ & 6.455 .236 & $9,37 \%$ & 2.038 .772 & $2,96 \%$ \\
\hline
\end{tabular}

Fuente: elaboración propia a partir de datos del Ministerio de Hacienda y Administraciones Públicas 
TABLA 6.- CLASIFICACIÓN ECONÓMICA CONSOLIDADA Y EJECUCIÓN DEL TOTAL DE ENTIDADES LOCALES (TOTAL NACIONAL). GASTO

\begin{tabular}{|c|c|c|c|c|c|c|c|c|c|c|}
\hline $\begin{array}{l}\text { C } \\
\text { A } \\
\text { p. }\end{array}$ & Gastos & $\begin{array}{c}\text { Derechos } \\
\text { Reconocidos } \\
\text { Netos (D.R.N) } \\
\text { (Avance 2013) }\end{array}$ & $\begin{array}{l}\text { D.R.N. } \\
\text { (2012) }\end{array}$ & $\begin{array}{l}\text { D.R.N. } \\
\text { (2011) }\end{array}$ & DIF 13-12 & $\%$ & DIF 12-11 & $\%$ & DIF 13-11 & $\%$ \\
\hline 1 & Gastos de personal & $19 \cdot 351.322$ & 18.283 .623 & 20.098 .645 & 1.067 .699 & $5,84 \%$ & -1.815 .023 & $-9,03 \%$ & -747.324 & $-3,72 \%$ \\
\hline 2 & $\begin{array}{l}\text { Gastos corrientes en } \\
\text { bienes y servicios }\end{array}$ & 18.622 .779 & 19.371 .881 & 18.914 .785 & -749.101 & $-3,87 \%$ & 457.095 & $2,42 \%$ & -292.006 & $-1,54 \%$ \\
\hline 3 & Gastos financieros & 1.699 .151 & 1.486 .019 & 1.154 .647 & 213.132 & $14,34 \%$ & 331.372 & $28,70 \%$ & 544.504 & $47,16 \%$ \\
\hline 4 & $\begin{array}{l}\text { Transferencias } \\
\text { corrientes }\end{array}$ & 14.310 .960 & 14.253 .770 & 14.885 .502 & 57.190 & $0,40 \%$ & -631.732 & $-4,24 \%$ & -574.542 & $-3,86 \%$ \\
\hline & Operaciones Corrientes & 53.984 .212 & 53.395 .292 & 55.053 .579 & 588.920 & $1,10 \%$ & -1.658 .287 & $-3,01 \%$ & -1.069 .368 & $-1,94 \%$ \\
\hline 6 & Inversiones reales & 5.129 .402 & 6.016 .711 & 9.899 .594 & -887.309 & $-14,75 \%$ & -3.882 .883 & $-39,22 \%$ & -4.770 .192 & $-48,19 \%$ \\
\hline 7 & $\begin{array}{l}\text { Transferencias de } \\
\text { capital }\end{array}$ & 627.139 & 1.005 .011 & 1.162 .828 & -377.873 & $-37,60 \%$ & -157.816 & $-13,57 \%$ & -535.689 & $-46,07 \%$ \\
\hline & Operaciones de Capital & 5.756 .540 & 7.021 .722 & 11.062 .422 & -1.265 .182 & $-18,02 \%$ & -4.040 .699 & $-36,53 \%$ & -5.305 .881 & $-47,96 \%$ \\
\hline & $\begin{array}{l}\text { Operaciones no } \\
\text { Financieras }\end{array}$ & 59.740 .752 & 60.417 .015 & 66.116 .001 & -676.262 & $-1,12 \%$ & -5.698 .987 & $-8,62 \%$ & -6.375 .249 & $-9,64 \%$ \\
\hline 8 & Activos financieros & 551.868 & 964.474 & 352.496 & -412.606 & $-42,78 \%$ & 611.978 & $173,61 \%$ & $199 \cdot 372$ & $56,56 \%$ \\
\hline 9 & Pasivos financieros & 5.178 .973 & 4.260 .343 & 3.250 .347 & 918.631 & $21,56 \%$ & 1.009 .996 & $31,07 \%$ & 1.928 .626 & $59,34 \%$ \\
\hline & $\begin{array}{l}\text { Operaciones } \\
\text { Financieras }\end{array}$ & 5.730 .841 & 5.224 .816 & 3.602 .843 & 506.025 & $9,69 \%$ & 1.621 .973 & $45,02 \%$ & 2.127 .998 & $59,06 \%$ \\
\hline & Total gastos & 65.471 .593 & 65.641 .831 & 69.718 .844 & -170.237 & $-0,26 \%$ & -4.077 .013 & $-5,85 \%$ & -4.247 .251 & $-6,09 \%$ \\
\hline
\end{tabular}

Fuente: elaboración propia a partir de datos del Ministerio de Hacienda y Administraciones Públicas

Un capítulo a resaltar, por la incidencia que tiene en la provisión de servicios públicos, es el gasto destinado a personal. Sin duda, es uno de los recursos que presenta un mayor grado de rigidez. La toma de decisiones relacionada con este capítulo tiene efectos de primer orden al tener una relación directa no sólo con las personas a las que se presta un servicio, sino también al desplegar consecuencias sobre aquellos ciudadanos, que en calidad de empleados al servicio de la Administración, prestan ese servicio.

Por lo tanto, se considera adecuado ofrecer los datos de su evolución al objeto de completar, aún más, la diferenciación en la gestión del ingreso y el gasto. Y dentro de éste último, la incidencia, para la toma de decisión, sobre aquellos considerados más estructurales (ver tablas 7 y 8 ).

Las conclusiones determinan las limitaciones para la gestión desde las que se parten en las entidades locales. Y no tanto, por la entrada en vigor de la nueva normativa local (LRSAL). Las decisiones autónomas de los propios gestores locales quedan más vinculadas a la situación económico-financiera de la entidad local y la necesidad de tomar decisiones en el corto plazo ajustando sus flujos de ingresos y gastos, que al cronograma que plantea la Ley de racionalización y sostenibilidad de la Administración local que entra en vigor el 31 de diciembre de 2.013.

TABLA 7. EVOLUCIÓN DEL PERSONAL DE LA ADMINISTRACIÓN LOCAL POR TIPOLOGÍA DE EMPLEADOS 2006-2014

\begin{tabular}{|c|c|c|c|c|c|c|c|c|c|c|c|}
\hline $\begin{array}{l}\text { Administración } \\
\text { Local: } \\
\text { Tipología de } \\
\text { empleados }\end{array}$ & 2006 & 2007 & 2008 & 2009 & 2010 & 2011 & 2012 & 2013 & 2014 & $\begin{array}{l}\text { Variación } \\
\text { 2006/2014 }\end{array}$ & $\begin{array}{l}\text { Variación \% } \\
2006-2014\end{array}$ \\
\hline Funcionarios & 199.441 & 205.230 & 212.705 & 213.985 & 215.621 & 217.785 & 220.573 & 218.529 & 213.433 & 13.992 & $7,02 \%$ \\
\hline $\begin{array}{l}\text { Personal } \\
\text { laboral }\end{array}$ & 339.049 & 359.537 & 371.453 & 371.331 & 397.958 & 386.152 & 336.430 & 293.726 & 309.480 & -29.569 & $-8,72 \%$ \\
\hline Otro personal & 33.829 & 37.234 & 39.056 & 44.189 & 44.326 & 43.551 & 40.209 & 37.552 & 37.861 & 4.032 & $11,92 \%$ \\
\hline Total EE.LL. & 572.319 & 602.001 & 623.214 & 629.505 & 657.905 & 647.488 & 597.212 & 549.807 & 560.774 & -11.545 & $-2,02 \%$ \\
\hline
\end{tabular}

Fuente: Boletín Estadístico del Personal al Servicio de las Administraciones Públicas, datos a 1 de enero de cada año. Efectivos por unidades. 


\section{Tipología de empleados}

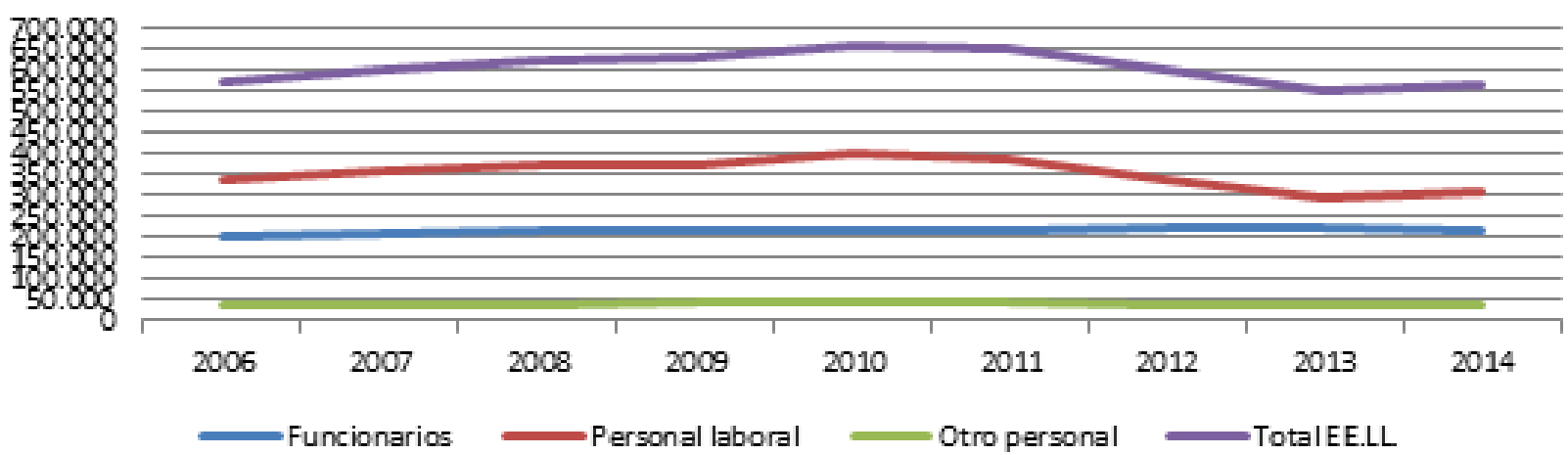

Bajo el argumento anterior, el hipotético impacto por un cambio normativo (paso de la Ley 7/1985 a Ley 27/2013) para este capítulo concreto queda más relacionado con la voluntad del propio gestor local ante la imposibilidad de aplazar medidas que afectan directamente al gasto estructural que los axiomas recogidos en la propia LRSAL, a los que cabe añadir periodos transitorios para la valoración, evaluación y toma de decisión sobre esta tipología de gasto.

TABLA 8.- EVOLUCIÓN DE PERSONAL DE LA ADMINISTRACIÓN LOCAL POR TIPOLOGÍA DE EMPLEADOS 2012-2014

\begin{tabular}{|l|c|c|c|c|}
\hline \multicolumn{1}{|c|}{ Administración Local } & Enero-12 & Julio-14 & Variación & $\%$ \\
\hline Ayuntamientos & 526.248 & 495.664 & -30.584 & $-5,81 \%$ \\
\hline Diputaciones/Cabildos/Consejos Insulares & 70.964 & 60.596 & -10.368 & $-14,61 \%$ \\
\hline Total & 597.212 & 556.260 & -40.952 & $-6,86 \%$ \\
\hline
\end{tabular}

Fuente: Boletín Estadístico del Personal al Servicio de las Administraciones Públicas, julio 2014. Efectivos por unidades.

En definitiva, los indicadores que se incorporan en la LRSAL conforme a la redacción de la LOEPSF en términos de estabilidad presupuestaria, sostenibilidad financiera y periodo medio de pago, ya eran parte de la preocupación de los gestores locales.

El cambio sustancial que incorpora el nuevo escenario es el seguimiento de los mismos, la publicación de los datos y las medidas de carácter correctivo y coercitivo que se implementan en caso de incumplimiento. Si aludimos al nuevo papel desempeñado por el gestor público, en términos económico-financieros, encontraremos la diferencia entre un comportamiento anterior de participación en la gestión y uno nuevo de sujeto proactivo para la gestión. Y este escenario, viene a completarse con el reforzamiento de la figura del interventor de la entidad.

Dejando a un lado el debate anterior. Y volviendo a los resultados. Como se puede comprobar, las Corporaciones Locales han conseguido logros notables en su gestión. Y por ende, también el conjunto de las Administraciones.

A la estabilidad presupuestaria y la sostenibilidad financiera, se suma el principio de lealtad institucional. La importancia de tener en cuenta la medición de aquellas decisiones que toma una Administración frente a otras, completa una visión coordinada de la relación interadministrativa que se pretende. Además, la cooperación entre la Administración General del Estado ha facilitado la mejora en la gestión de las Entidades locales con efectos positivos:

1.- La necesaria inyección de liquidez que consolida el nuevo escenario aprobado en 2011 queda demostrada en (1) el aplazamiento a 120 mensualidades, en lugar de las 60 exigidas, para la devolución de los 6.000 millones de euros por las liquidaciones negativas de los ejercicios de 2008 y 2009 con un incremento de liquidez sólo para el año 2012, de 620 millones de euros; (2) el adelanto del 50\% de la liquidación del ejercicio de 2010 a favor de las Entidades Locales por un importe de 1.000 millones de euros para el conjunto de las arcas municipales; (3) la aplicación de manera transitoria y excepcional durante los ejercicios 2012 y 2013 para los inmuebles urbanos de un incremento del tipo impositivo del IBI con un incremento de recaudación de 918 millones de euros; (4) las diversas medidas tributarias y administrativas adoptadas en marzo de 2012, dotando de una mayor autonomía financiera a los Ayuntamientos en el Impuesto sobre el Incremento de Valor de los Terrenos de Naturaleza Urbana; (5) los sucesivos planes de pago a proveedores para identificar facturas no contabilizadas y posteriormente proceder al 
pago pendiente por importe de 11.563,4 millones de euros; (6) los Reales Decretos-ley de 20/2012 de medidas para garantizar la estabilidad presupuestaria y de fomento de la competitividad y 21/2012, de medidas de liquidez de las Administraciones públicas incorporan un conjunto de medidas que suponen un ahorro para las Entidades Locales de 1.176,5 millones de euros; (7) los Presupuestos Generales del Estado que consolidan año tras año (2012-2015) su apoyo a la administración más cercana, nuestros Ayuntamientos, Diputaciones, Consejos y Consells insulares para asegurar la sostenibilidad en la prestación de servicios básicos a los ciudadanos con un incremento adicional del 4,8\% en 2015 respecto al año anterior lo que supone 787 millones de euros más, situándose en los 17.210 millones de euros; (8) la ampliación del periodo de reintegro de las liquidaciones negativas del ejercicio 2013 por importe de 819,6 millones de euros; (9) y los mecanismos de retención de la Participación de los Tributos del Estado como garantía financiera en relación a las cantidades pendientes de pago por parte de las Comunidades Autónomas a las Entidades Locales, fundamentalmente para los gastos relacionados con sanidad, educación y servicios sociales. La garantía de cobro al proveedor en tiempo y forma como compromiso de todas las Administraciones bajo el amparo del principio de sostenibilidad financiera.

2.- La implantación del mecanismo del Plan de pago a proveedores como elemento dinamizador y transformador del modelo anterior. Se constituye como un elemento clave para aflorar deuda comercial y convertirla en financiera al objeto de adecuar los flujos de ingresos de la Administración a los pagos. Desarrollado en tres fases aprobadas por los Reales Decretos-Ley 4/2012, de 24 de febrero; 4/2013, de 22 de febrero, y 8/2013, de 28 de junio. A finales de 2013, se habían pagado 11.563,4 millones de euros (ver tabla 9) correspondientes a 2.097.357 facturas, lo que ha permitido salvar y dar viabilidad a pymes y autónomos avocados a la quiebra ante el impago de las Administraciones. Con la aprobación del RD-L 8/2013, se pone en marcha la tercera fase de este Plan destinado a ayudar a las entidades locales, en este caso, a reducir la deuda comercial acumulada.

TABLA 9. CLASIFICACIÓN POR CC.AA. DE LOS RESULTADOS DE ENTIDADES LOCALES EN LOS PLANES DE PAGO A PROVEEDORES

(EN MILES DE EUROS)

\begin{tabular}{|c|c|c|c|c|c|c|c|c|}
\hline $\begin{array}{l}\text { Comunidades } \\
\text { Autónomas }\end{array}$ & $\begin{array}{l}\text { Primera } \\
\text { Fase }\end{array}$ & $\begin{array}{l}\% / \text { Total } \\
1^{\text {a }} \text { Fase }\end{array}$ & $\begin{array}{l}\text { Segunda } \\
\text { Fase }\end{array}$ & $\begin{array}{l}\% / \text { Total } \\
2^{\text {a }} \text { Fase }\end{array}$ & $\begin{array}{c}\text { Tercera } \\
\text { Fase }\end{array}$ & $\begin{array}{l}\% / \text { Total } \\
3^{\text {a Fase }}\end{array}$ & $\begin{array}{c}\text { Total } \\
\text { Proveedores } \\
\text { EE.LL. }\end{array}$ & $\begin{array}{c}\% / \text { Total } \\
\text { de Fases }\end{array}$ \\
\hline Andalucía & $2.814 .052,62$ & $29 \%$ & $137 \cdot 946,62$ & $68 \%$ & $452.943,08$ & $25 \%$ & $3.404 \cdot 942,32$ & $29 \%$ \\
\hline Aragón & $225.048,74$ & $2 \%$ & 604,62 & $0 \%$ & $1.735,52$ & $0 \%$ & $227.388,88$ & $2 \%$ \\
\hline Asturias & $76.242,99$ & $1 \%$ & 631,63 & $0 \%$ & $5.363,26$ & $0 \%$ & $82.237,88$ & $1 \%$ \\
\hline C. Valenciana & $1.113 .711,48$ & $12 \%$ & $16.290,55$ & $8 \%$ & $140.764,80$ & $8 \%$ & $1.270 .766,83$ & $11 \%$ \\
\hline Canarias & $442.511,50$ & $5 \%$ & 18,42 & $0 \%$ & $59 \cdot 431,62$ & $3 \%$ & $501.961,54$ & $4 \%$ \\
\hline Cantabria & $50.474,53$ & $1 \%$ & 147,46 & $0 \%$ & 263,88 & $0 \%$ & $50.885,87$ & $0 \%$ \\
\hline Castilla-León & $426.827,49$ & $4 \%$ & $2.205,44$ & $1 \%$ & $24.233,50$ & $1 \%$ & $453.266,43$ & $4 \%$ \\
\hline $\begin{array}{l}\text { Castilla- La } \\
\text { Mancha }\end{array}$ & $451.311,00$ & $5 \%$ & $11.590,26$ & $6 \%$ & $106.334,83$ & $6 \%$ & $569.236,09$ & $5 \%$ \\
\hline Cataluña & $645.603,41$ & $7 \%$ & $3.303,40$ & $2 \%$ & $171.567,51$ & $10 \%$ & $820.474,32$ & $7 \%$ \\
\hline Extremadura & $121.458,60$ & $1 \%$ & $1.776,38$ & $1 \%$ & $29 \cdot 531,26$ & $2 \%$ & $152.766,24$ & $1 \%$ \\
\hline Islas Baleares & $299.772,69$ & $3 \%$ & $5 \cdot 527,53$ & $3 \%$ & $144.668,22$ & $8 \%$ & $449 \cdot 968,44$ & $4 \%$ \\
\hline C. Madrid & $2.277 \cdot 993,60$ & $24 \%$ & $12.497,69$ & $6 \%$ & $591.394,06$ & $33 \%$ & $2.881 .885,35$ & $25 \%$ \\
\hline Murcia & $367.262,23$ & $4 \%$ & $3.767,61$ & $2 \%$ & $47.934,61$ & $3 \%$ & $418.964,45$ & $4 \%$ \\
\hline Rioja & $6.980,93$ & $0 \%$ & 0,00 & $0 \%$ & 153,56 & $0 \%$ & $7.134,49$ & $0 \%$ \\
\hline Galicia & $196.963,97$ & $2 \%$ & $5.979,95$ & $3 \%$ & $17.369,09$ & $1 \%$ & $220.313,01$ & $2 \%$ \\
\hline Navarra & 0,00 & $0 \%$ & $1.156,24$ & $1 \%$ & 0,00 & $0 \%$ & $1.156,24$ & $0 \%$ \\
\hline Ceuta & $82.124,72$ & $1 \%$ & 0,00 & $0 \%$ & 0,00 & $0 \%$ & $82.124,72$ & $1 \%$ \\
\hline TOTAL & $9.598 .340,50$ & $100 \%$ & $203.443,80$ & $100 \%$ & $1.793 .688,80$ & $100 \%$ & $11.595 .473,10$ & $100 \%$ \\
\hline
\end{tabular}

Fuente: elaboración propia a partir de datos del Ministerio de Hacienda y Administraciones Públicas 

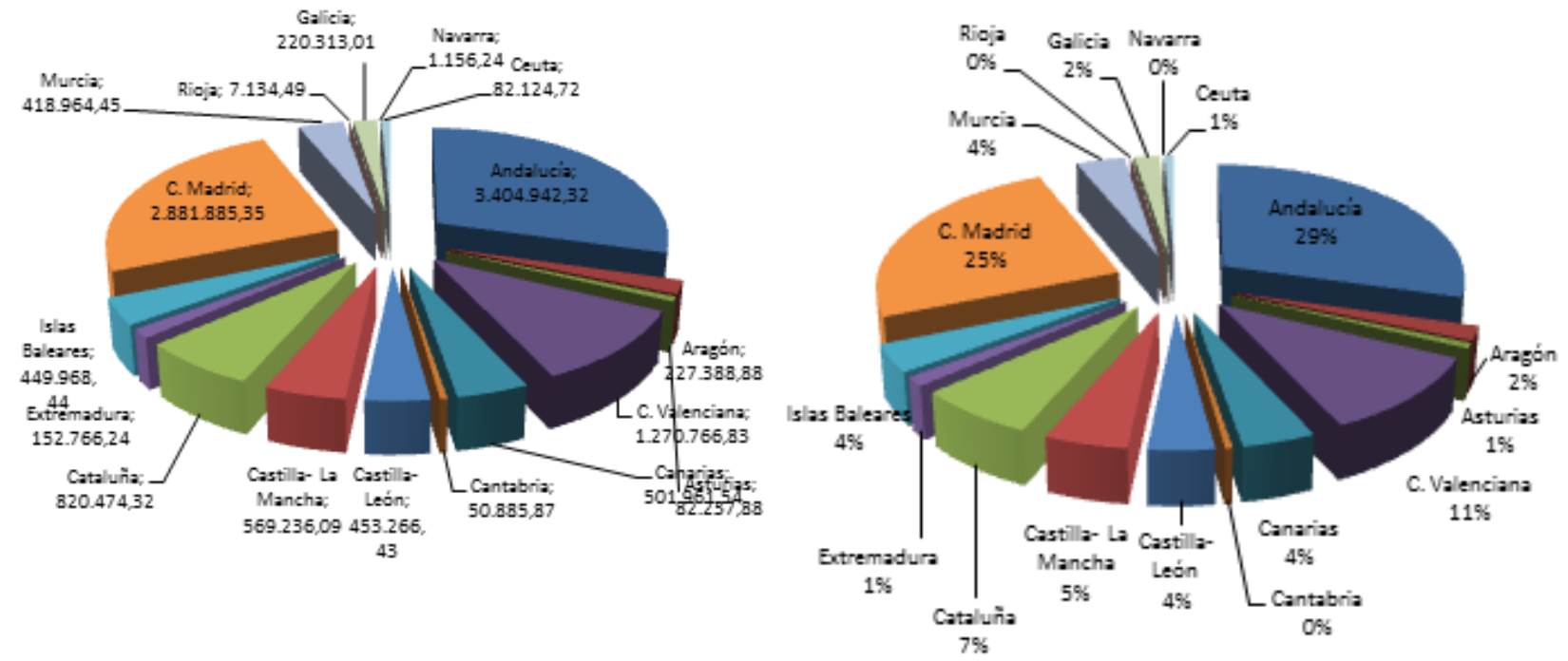

Los efectos positivos sobre la evolución reciente de las facturas pendientes de pago en las Administraciones Públicas no se hicieron esperar al aflorar pagos no contabilizados, transformarlos en deuda comercial y ofrecer una solución adapta al flujo de ingresos y pagos generado por la entidad local mediante su adaptación en deuda financiera. Por lo tanto, los sucesivos planes han permitido desbloquear pagos y canalizar fondos a la economía. La dotación de liquidez, sin duda, ha tenido un efecto dinamizador para la actividad económica. Y en paralelo, también han supuesto un aumento del endeudamiento de las economías locales con el Estado.

Es difícil valorar el impacto real en la economía por la disparidad de criterios sobre la incorporación de variables significativas a un modelo de cálculo. Sirva, a modo de ejemplo, el reciente estudio publicado por el Banco de España ${ }^{4}$ que cuantifica bajo dos modelos de cálculo distintos y con distinto grado de condicionalidad, un impacto sobre el Producto Interior Bruto (en adelante, PIB) de todas las fases del Plan de Pago a Proveedores que incorpora al conjunto de las Administraciones Públicas y no sólo a la local, de 0,55 puntos de PIB acumulados según la metodología del modelo VAR y que amplía su estimación a 0,6 puntos de PIB de forma acumulada hasta 2014 y 0,7 puntos de empleo según los resultados obtenidos bajo las simulaciones realizadas con el modelo trimestral del Banco de España (MTBE). Los dos estudios vienen a refrendar la idoneidad de la medida al mismo tiempo que aconsejan el seguimiento de los planes de ajuste relacionados con los mismos (relacionado con la información contenida en la tabla 15).

3.- En el marco del seguimiento del principio de sostenibilidad financiera. Se proyecta el Real Decreto-ley 17/2014, de 26 de diciembre, de medidas de sostenibilidad financiera de las comunidades autónomas y entidades locales y otras de carácter económico para garantía en el cumplimiento del control de la deuda comercial, la transparencia de las Administraciones Públicas y una adaptación y seguimiento de los periodos medios de pago a los proveedores.

Con especial incidencia, en aquellos gastos de naturaleza social. Es importante destacar la inclusión de una modificación sustancial del texto refundido de la Ley reguladora de las Haciendas Locales, que incorpora el principio de prudencia financiera para todas las operaciones financieras que suscriban las Corporaciones Locales al objeto de minimizar el riesgo y coste de las operaciones financieras. Esta medida dota de una mayor rigidez al concepto de sostenibilidad financiera y vincula de una forma directa a la Administración Local con la Administración General del Estado y, en concreto, con las resoluciones que a tal efecto se dispongan desde la Secretaría General del Tesoro y Política Financiera del Estado.

Por este motivo, se promueve una nueva reforma estructural a favor de las entidades locales. Al asumir el Estado necesidades de financiación de la Administración territorial, en este caso, la local. En este caso, los ahorros generados (ver tabla 10) se trasladan de una manera efectiva al ámbito local. Este ejercicio identifica las consecuencias de una gestión coordinada. Al activar las "ganancias" de la gestión financiera estatal a la actividad

4 Delgado Téllez, M; Hernández de Cos, P; Hurtado, S; Pérez, J. “Los mecanismos extraordinarios de pago a proveedores de las Administraciones Públicas en España. Documentos ocasionales. Nº1501 (2015). Madrid. ISSN: 1696-2230 (edición electrónica). 
ordinaria local. Lo que supone un estímulo para reforzar los capítulos vinculados al gasto corriente ${ }^{5}$, al seguimiento de los gastos de inversión ${ }^{6}$ y el control reforzado de aquellas entidades con dificultad financiera ${ }^{7}$

Al mismo tiempo, la mutualización que se produce no supone un cambio de competencias, sino la creación con carácter temporal, de una ayuda, que bajo el principio de lealtad institucional, el Estado ofrece al objeto de trasladar las condiciones actuales de los mercados financieros. Así se cumple con los objetivos de estabilidad presupuestaria y por la sostenibilidad financiera de los servicios básicos que se prestan al ciudadano.

TABLA 10. AHORROS EN MECANISMOS DE LIQUIDEZ (FONDO DE LIQUIDEZ AUTONÓMICA Y FONDO PROVEEDORES)

(MILLONES EUROS)

\begin{tabular}{|c|c|c|c|c|}
\hline \multirow{4}{*}{$\begin{array}{l}\text { Total } \\
\text { Entidades Locales }\end{array}$} & \multicolumn{2}{|c|}{ Deuda total 30.06.14 } & \multicolumn{2}{|c|}{$\begin{array}{l}\text { \% Deuda FLA y FFPP sobre deuda } \\
30.06 .14\end{array}$} \\
\hline & \multicolumn{2}{|c|}{41.994} & \multicolumn{2}{|c|}{$21,95 \%$} \\
\hline & $\begin{array}{l}\text { Ahorro } \\
\text { reestructuración } \\
\text { FLA y FFPP } 2015 \\
\text { (julio 2014) }\end{array}$ & $\begin{array}{l}\text { Ahorro } \\
\text { reestructuración } \\
\text { FLA y FFPP 2015 } \\
\text { (diciembre 2014) }\end{array}$ & $\begin{array}{l}\text { Ahorro } \\
\text { nuevas } \\
\text { emisiones } \\
\text { (nuevos } \\
\text { mecanismos) }\end{array}$ & Total \\
\hline & 750,31 & 511,2 & 189,35 & $1.450,86$ \\
\hline
\end{tabular}

Fuente: Ministerio de Hacienda y Administraciones Públicas

La convergencia entre el principio de sostenibilidad financiera y el principio de transparencia en la información se hace efectiva mediante los mecanismos que arbitra la economía de la información ${ }^{8}$.

No sólo es necesario ofrecer una mayor transparencia hacia los ciudadanos y las empresas al facilitar información sobre los periodos medios de pago ${ }^{9}$ mediante la implantación de la Ley Orgánica 9/2013 de control de deuda comercial en el sector público.

Además, mediante la Ley 25/2013 de impulso de la factura electrónica y creación del registro contable de facturas en el Sector Público, se procede a la implantación de la factura electrónica, el registro contable y al impulso de la Administración Electrónica como procedimiento que refuerza el control en la facturación para dotar de mayores garantías a aquellos autónomos, empresas y ciudadanos que trabajan o realizan alguna tramitación con la Administración.

Así, las entidades locales, según sus características, publican sus periodos medios de pago con una periodicidad mensual o trimestral ${ }^{10}$.

Todo lo anterior, conforma un escenario de continuo seguimiento por parte de la Administración General del Estado (ver tabla 11 y 12) en aras a incorporar una transparencia revisable y que retroalimente los correspondientes mecanismos de corrección si éstos son necesarios (tal como dispone el Fondo de Ordenación creado en el RD-I 17/2014).

TABLA 11. PERIODO MEDIO DE PAGO A PROVEEDORES EN EL MES DE NOVIEMBRE DE 2014. MODELO DE CESIÓN. EN DÍAS

\begin{tabular}{|c|c|c|c|c|c|c|}
\hline Periodo & Modelo & $\begin{array}{c}\text { Ratio de } \\
\text { Operaciones } \\
\text { Pagadas }\end{array}$ & $\begin{array}{c}\text { Importe de } \\
\text { Pagos } \\
\text { Realizados }\end{array}$ & $\begin{array}{c}\text { Ratio de } \\
\text { Operaciones } \\
\text { Pendientes de } \\
\text { Pago }\end{array}$ & $\begin{array}{c}\text { Importe de } \\
\text { Pagos } \\
\text { Pendientes }\end{array}$ & $\begin{array}{c}\text { Periodo } \\
\text { Medio } \\
\text { de Pago }\end{array}$ \\
\hline Noviembre 2014 & Cesión & 18,17 & $823.363 .391,61 €$ & 31,80 & $1.377 .605 .299,22 €$ & 26,70 \\
\hline
\end{tabular}

Fuente: Ministerio de Hacienda y Administraciones Públicas

5 Disposición adicional séptima del RD-I 17/2014. Las operaciones de crédito que se formalicen en 2015 las Entidades Locales con cargo al Fondo de Financiación a Entidades Locales tendrán un tipo de interés para ese año del o\% anual. Las operaciones de préstamo formalizadas con cargo al Fondo para la Financiación de los Pagos a Proveedores, por operaciones formalizadas en las tres fases de ese mecanismo de pago, a partir de 1 de enero de 2015 tendrán un tipo de interés del 0\% anual y no abonarán vencimientos de principal, condiciones aplicables en ese año, Además el plazo de amortización de esas operaciones se amplía en un año. Con esta propuesta, se permite a las Administraciones territoriales acceder a la mejora de los costes de financiación del Estado. Todo lo anterior, bajo los principios ya mencionados.

6 Título III. Capítulo II. Artículos 50-54. Compartimento Fondo de Impulso Económico del RD-I 17/2014

7 Título III. Capítulo I. Artículos 39-49. Compartimento Fondo de Ordenación del RD-I 17/2014

8 Cabañes, M.L; Lorca, A. Microeconomía. Thomson Civitas. 3 a edición. 2006. Navarra. 84-470-2501-2

9 Http://www.minhap.gob.es/es-ES/CDI/PMP/Paginas/PMPdelasAAPP.aspx

10 Las Corporaciones Locales que son capital de provincia, de comunidad autónoma o superan los 75.000 habitantes y las Diputaciones, Consejos y Cabildos insulares publican sus datos cada mes. El resto trimestralmente. 
TABLA 12. PERIODO MEDIO DE PAGO A PROVEEDORES (SEPTIEMBRE 2014-NOVIEMBRE 2014). MODELO DE CESIÓN. EN DÍAS

\begin{tabular}{|c|c|c|c|c|}
\hline Periodo & Modelo & $\begin{array}{c}\text { Ratio } \\
\text { operaciones } \\
\text { pagadas }\end{array}$ & $\begin{array}{c}\text { Ratio } \\
\text { operaciones } \\
\text { pendientes } \\
\text { de pago }\end{array}$ & $\begin{array}{c}\text { Periodo Medio } \\
\text { de pago }\end{array}$ \\
\hline Septiembre 2014 & Cesión & 15,87 & 33,16 & 24,96 \\
\hline Octubre 2014 & Cesión & 14,80 & 31,71 & 24,75 \\
\hline Noviembre 2014 & Cesión & 18,17 & 31,80 & 26,70 \\
\hline
\end{tabular}

Fuente: Ministerio de Hacienda y Administraciones Públicas

Las órdenes HAP/2105/2012 de suministro de información, HAP/2075/2014 sobre el cálculo del coste efectivo y HAP/419/2014 de estructura de presupuestos de las Entidades Locales se convierten en herramientas básicas para homogeneizar la información al objeto de medir y comparar las diferentes estructuras municipales para poder hacer un seguimiento conjunto sobre su evolución y facilitar una mayor información al ciudadano y las empresas que trabajan para las Administraciones. A las que conviene enmarcar dentro del impulso que se está desarrollando en términos de transparencia y desarrollo de la Administración electrónica⒈

La mejora de las condiciones financieras para el conjunto de la Administración local incorporada en el Real Decreto-ley 17/2014, de 26 de diciembre, de medidas de sostenibilidad financiera de las comunidades autónomas y entidades locales y otras de carácter económico de colaboración del Estado con las Administraciones territoriales en la gestión de su política financiera tiene su anclaje, al igual que el resto de la normativa desarrollada tras la modificación del citado artículo 135, en la Ley Orgánica 2/2012, de 27 de abril, de Estabilidad Presupuestaria y Sostenibilidad Financiera. Y lo hace no sólo bajo el seguimiento de los principios que venimos analizando, sino también en los términos que incorporan los principios de plurianualidad, responsabilidad y lealtad institucional ${ }^{12}$.

4.- La prioridad por garantizar el pago de los gastos relacionados con la sociedad del bienestar en términos de sostenibilidad financiera queda integrada en el modelo bajo los Fondos de Liquidez autonómica (FLA) y los Fondos de Pago a Proveedores (FF.PP).

Otro ejemplo más del despliegue efectivo del concepto de sostenibilidad financiera lo encontramos en el Fondo de Liquidez Autonómico denominado “FLA social”. Medida incluida en el Real Decreto-ley 17/2014, de 26 de diciembre, de medidas de sostenibilidad financiera de las comunidades autónomas y entidades locales y otras de carácter económico que refuerza el compromiso con la sociedad del bienestar y prioriza el gasto social a través de un fondo dotado con 1.000 millones de euros (ver figura 13).

Así, como resultado de la reforma local, se está llevando a cabo una ordenación del reparto de las competencias entre la Administración autonómica y local. Se crea este mecanismo de apoyo a la liquidez de las Comunidades Autónomas de carácter temporal y voluntario que financiará el pago de las obligaciones pendientes a 31 de diciembre de 2014 con las Entidades Locales, que deriven de convenios o transferencias pendientes de pago en materia social. Un ejemplo más, de la vinculación normativa (LOEPSF, LO 9/2013 y LRSAL).

La creación de un registro electrónico de $\operatorname{convenios}^{13}$ en el que las Comunidades Autónomas deberán inscribir los convenios suscritos con las Entidades Locales que impliquen obligaciones financieras o compromisos de pago a cargo de las Comunidades Autónomas, siendo el interventor local el responsable para aportar esa información, vuelve a reforzar la idea de una gestión proactiva y vinculada de manera directa con la figura del interventor.

En el caso de las Comunidades Autónomas que no se adhieran al Fondo Social o que incumplan sus obligaciones de pago, el mecanismo se refuerza con el procedimiento de retención o deducción de recursos por el Estado para la cancelación de dichas obligaciones. Esto supone un paso más en la estrategia de una Administración sin costuras, donde se tenga una visión conjunta de las Administraciones al servicio del ciudadano, desde una perspectiva, en este caso, de gestión económica.

11 Ley $25 / 2013$, de 27 de diciembre, de impulso de la factura electrónica y creación del registro contable de facturas en el Sector Público; Ley Orgánica 9/2013, de 20 de diciembre, de control de la deuda comercial en el sector público; Ley 19/2013, de 9 de diciembre, de transparencia, acceso a la información pública y buen gobierno.

12 Artículo 5, 8 y 9 de la LO 2/2012.

13 Herramienta a través de la cual las Entidades Locales pueden de comprobar si las Comunidades Autónomas incluyen sus deudas por convenios y transferencias “sociales" en el sistema previsto en el RDL 17/2014, es a través de la AEAT. La información es accesible mediante certificado electrónico en el portal de la AEAT: http://www.agenciatributaria.es/ en el apartado "Acceda directamente” se encuentra el enlace "EELL FLA social y Morosidad" donde se encuentran las funcionalidades.

REALA, n 3, enero-junio 2015, ISSN: 1989-8975 - DOI: http://dx.doi.org/10.24965/reala.v0i3.10242 
TABLA 13. TRANSFERENCIAS RECIBIDAS POR ENTIDADES LOCALES (POLÍtICA DE GASTO 23. PARTIDAS 450 Y 750). PERIODO 2010-2013

\begin{tabular}{|l|c|c|c|}
\hline \multicolumn{1}{|c|}{ CONCEPTOS } & $\begin{array}{c}\text { Transferencias } \\
\text { corrientes }\end{array}$ & $\begin{array}{c}\text { Transferencias } \\
\text { Capital }\end{array}$ & Total \\
\hline $\begin{array}{l}\text { Transferencias por convenios } \\
\text { suscritos con la CC. AA. en } \\
\text { materia de Servicios Sociales }\end{array}$ & 509 & -5 & 504 \\
\hline $\begin{array}{l}\text { Transferencias por convenios } \\
\text { suscritos con la CC. AA. en } \\
\text { materia de Educación }\end{array}$ & 102 & 9 & 111 \\
\hline $\begin{array}{l}\text { Transferencias por convenios } \\
\text { suscritos con la CC. AA. en } \\
\text { materia de Empleo y Desarrollo }\end{array}$ & 84 & 43 & 127 \\
\hline $\begin{array}{l}\text { Otras transferencias por otros } \\
\text { convenios suscritos con la CC. } \\
\text { AA. }\end{array}$ & 95 & 130 & 225 \\
\hline \multicolumn{1}{|c|}{ TOTAL } & 790 & 177 & 967 \\
\hline
\end{tabular}

Fuente: elaboración propia a partir de datos del Ministerio de Hacienda y Administraciones Públicas

5.- La inversión financieramente sostenible es un concepto acuñado bajo el nuevo marco de la estabilidad y sostenibilidad. La modificación de la Ley de Estabilidad Presupuestaria para fijar las condiciones por las que una inversión se considera financieramente sostenible incorpora modificaciones estructurales respecto al tradicional concepto de inversión.

La condicionalidad que incluye la LOEPSF extiende sus efectos para las inversiones proyectadas por entidades locales con acreditada solvencia según recoge el concepto definido en su artículo 4. Y todo lo anterior, queda enmarcado en un esquema integrado (ver figura 14) y bajo un criterio de revisión temporal de carácter anual.

TABLA 14. REGLAS ESPECIALES PARA LA APLICACIÓN DEL SUPERÁVIT PRESUPUESTARIO.

DOS REQUISITOS PREVIOS:

1.- Cumplir o no superar los límites de la LHL en materia de autorización para endeudamiento: >110\% de ingresos corrientes

2.- Ejercicio inmediato anterior: SUPERÁVIT EN CONTABILIDAD NACIONAL+ (Total de Ingresos en contabilidad nacional (A) - Total de Gastos en contabilidad nacional (B) = Capacidad/Necesidad de Financiación (C)) REMANENTE DE TESORERÍA POSITIVO PARA GASTOS GENERALES (acumulación de resultados presupuestarios de ejercicios anteriores con signo positivo)

LA MENOR CUANTÍA DE ESTAS DOS CIFRAS:

SUPERÁVIT EN CONTABILIDAD NACIONAL / REMANENTE DE TESORERÍA PARA GASTOS GENERALES

A LAS QUE SE RESTARÁ

- Obligaciones de la cuenta "Acreedores por operaciones pendientes de aplicar a presupuesto"

-Obligaciones pendientes de pago del ejercicio anterior con proveedores, contabilizadas y aplicadas

= RESULTADO POSITIVO Y CORPORACIÓN LOCAL OPTA POR INVERSIÓN

- \% saldo positivo pendiente para amortizar operaciones de endeudamiento vigentes en 2014 para no incurrir en déficit en contabilidad nacional

= SALDO DISPONIBLE POSITIVO

CARACTERÍSTICAS DE LA INVERSIÓN A REALIZAR CON EL SALDO DISPONIBLE

LAS CARACTERÍSTICAS DE LA INVERSIÓN A REALIZAR CON EL SALDO DISPONIBLE RESTANTE SERÁN CON CARÁCTER ACUMULADO: INVERSIÓN FINANCIERAMENTE SOSTENIBLE EN SU VIDA ÚTIL + GENERACIÓN DE CRECIMIENTO ECONÓMICO A LARGO PLAZO + CUMPLIMIENTO DE PERIODO MEDIO DE PAGO A PROVEEDORES (30 DÍAS) NO SUPERE PLAZO MÁXIMO (30 DÍAS) $=60$ DÍAS $•$

Fuente: elaboración propia a partir de la interpretación del RD-I 2/2014, de 21 de febrero. Medida revisada y prorrogada en 2015 mediante el RD-I 17/2014, de 26 de diciembre en su disposición adicional novena.

- A la condicionalidad contenida en la tabla se añade el requisito de autorización previa por parte del MINHAP para inversiones superiores a 10 millones de euros y la obligación formal de incluir una memoria económica suscrita por el Presidente de la Corporación con un informe del órgano interventor que contenga las correspondientes proyecciones presupuestarias.

Así, mediante la publicación del Real Decreto-Ley 2/2014, se da cumplimiento a la disposición adicional sexta de la Ley Orgánica 2/2012, de 27 de abril, de Estabilidad Presupuestaria y Sostenibilidad Financiera. Y por lo tanto, 
se posibilita la ejecución de inversiones en el ejercicio 2014 por las entidades locales saneadas financieramente y que presenten unos indicadores de estabilidad presupuestaria, deuda y periodo medio de pago a proveedores con una suficiente solidez financiera para afrontar inversiones de interés para los ciudadanos del municipio.

La prórroga de la inversión del superávit en inversiones financieramente sostenibles para el ejercicio 2015 en las mismas condiciones del ejercicio 2014, medida incluida en el Real Decreto-ley 17/2014, de 26 de diciembre, de medidas de sostenibilidad financiera de las comunidades autónomas y entidades locales y otras de carácter económico supone la constatación tanto del seguimiento realizado a este tipo de inversiones por parte de la Administración, como el refrendo que con carácter anual se hace a esta medida.

También, mediante el Fondo de Impulso Económico: dirigido a los municipios que cumplan los objetivos de estabilidad presupuestaria (no gastar más de lo que se ingresa), deuda pública (endeudamiento) y no excedan el periodo medio de pago a proveedores (más de 30 días el plazo máximo previsto en la normativa sobre morosidad, que son otros 30 días. En total, 60 días) durante los dos últimos meses previos a la solicitud y estén al corriente de sus obligaciones de suministro de información económico-financiera, se constata el cambio de modelo, su seguimiento y un apoyo condicionado a una solvencia revisable y demostrada.

La dotación de este fondo suma los 130 millones de euros. Es otra de las medidas incluidas en el Real Decretoley 17/2014, de 26 de diciembre, de medidas de sostenibilidad financiera de las comunidades autónomas y entidades locales y otras de carácter económico, destinado a aquellas entidades locales con acreditada salud financiera.

La garantía de atender, si fuese preciso, los vencimientos de los préstamos a largo plazo vinculados a inversiones financieramente sostenibles y un apoyo directo para la cobertura a largo plazo de inversiones consideradas relevantes, financieramente sostenibles y con capacidad de movilizar financiación para inversiones en el marco del Plan Juncker, nos ofrece un nuevo ejemplo del nivel de vinculación y planificación normativa desarrollada. El grado de seguimiento y condicionalidad que presenta la LOEPSF vuelve a desplegar sus efectos.

En este sentido, se puede afirmar, siempre bajo la observación de cada vez más contadas excepciones, que los gobiernos locales han conseguido gracias a un ejercicio de austeridad y adaptación de estructuras, bajo los correspondientes parámetros de seguimiento y control (consultar tabla 15); el cumplimiento de los principios de estabilidad presupuestaria y sostenibilidad financiera; una continua reducción de la deuda comercial; el mantenimiento de los servicios públicos básicos bajo un reforzamiento de sus garantías financieras; y cada vez en un número mayor, las entidades locales comienzan a destinar su superávit a inversiones ${ }^{14}$.

TABLA 15. INSTRUMENTOS DE CONTROL. FINALIDAD Y EFECTOS

\begin{tabular}{|c|c|}
\hline INSTRUMENTO CONTROL & FINALIDAD \\
\hline $\begin{array}{l}\text { Planes de ajuste } \\
(2.500 \text { entidades*) }\end{array}$ & $\begin{array}{l}\text { Acceso a medidas extraordinarias de liquidez: } \\
\text { Formalización de préstamos en el mecanismo de pagos a proveedores, con duración de } 10 \text { años. } \\
\text { En el caso de que se modifique el período de amortización de los préstamos de la } 1^{\text {a }} \text { fase de dicho } \\
\text { mecanismo, la duración será de } 20 \text { años } \\
\text { Ampliación del período de reintegro de las liquidaciones negativas de la PTE de } 2008 \text { y } 2009 \text {, con } \\
\text { duración hasta el reintegro total (10 años) } \\
\text { Acceso a las medidas extraordinarias del Título II del Real Decreto-ley 8/2013, con duración de } 10 \text { años }\end{array}$ \\
\hline $\begin{array}{l}\text { Planes económico-financieros } \\
(581 \text { entidades**) }\end{array}$ & $\begin{array}{l}\text { Corrección de incumplimiento del objetivo de estabilidad presupuestaria o de la regla de gasto. } \\
\text { Vigencia hasta el final del ejercicio siguiente a aquel en el que constaten los incumplimientos }\end{array}$ \\
\hline INSTRUMENTO CONTROL & EFECTOS DE INCUMPLIMIENTOS \\
\hline Planes económico-financieros & $\begin{array}{l}\text { Medidas coercitivas y de cumplimiento forzoso establecidas en los artículos } 25 \text { y } 26 \text { de la LO 2/2012: } \\
\text { depósito obligatorio en el Banco de España, indisponibilidad de créditos, intervención de la entidad y, } \\
\text { en última instancia, disolución de los órganos de la corporación local }\end{array}$ \\
\hline Planes de ajuste & \\
\hline
\end{tabular}

* Plan Presupuestario 2015. Reino de España. 15-10-2014. Página 40.

** Plan Presupuestario 2015. Reino de España. 15-10-2014. Página 41.

Los resultados son concluyentes y al mismo tiempo parecían inalcanzables en fechas no muy lejanas. La evolución tal como recoge la tabla 16, supone un resultado muy positivo en términos de evolución sobre la

14 En el margen habilitado por la LO 2/2012 en su relación con el concepto de Inversión Financieramente Sostenible y dentro de los márgenes permitidos por el techo de gasto.

REALA, n 3, enero-junio 2015, ISSN: 1989-8975 - DOI: http://dx.doi.org/10.24965/reala.v0i3.10242 
aportación realizada por la Administración local al conjunto de la Administración territorial en su relación con el cumplimiento de los objetivos comprometidos por España ante sus socios europeos.

TABLA 16. EVOLUCIÓN POR NÚMERO DE CORPORACIONES LOCALES SEGÚN EL SALDO PRESUPUESTARIO NO FINANCIERO (SNF)

\begin{tabular}{|c|c|c|c|c|c|c|c|c|}
\hline AÑO & $\begin{array}{l}\text { Número de } \\
\text { corporaciones } \\
\text { locales que } \\
\text { presentaron } \\
\text { liquidaciones }\end{array}$ & $\%$ & \begin{tabular}{|} 
Número de \\
corporaciones \\
locales que \\
presentaron \\
saldo \\
presupuestario \\
no financiero $>0$
\end{tabular} & $\%$ & \begin{tabular}{|c|} 
Número de \\
corporaciones \\
locales que \\
presentaron \\
saldo \\
presupuestario \\
no financiero \\
$<0$ \\
\end{tabular} & $\%$ & $\begin{array}{l}\text { Importe del } \\
\text { SNF positivo } \\
\text { (millones } \\
\text { euros) }\end{array}$ & $\begin{array}{c}\text { Importe del SNF } \\
\text { negativo } \\
\text { (millones euros) }\end{array}$ \\
\hline 2010 & 7.845 & 96,6 & 3.874 & 49,3 & 3.559 & 45,3 & 1.717 & 3.161 \\
\hline 2011 & 8.020 & 98,8 & 4.162 & 51,9 & 3.364 & 41,9 & 1.630 & 2.294 \\
\hline 2012 & 8.011 & 98,7 & 5.551 & 69,2 & 1.974 & 24,6 & 4.739 & 1.164 \\
\hline 2013 & 8.098 & 99,7 & 6.413 & 79,1 & 773 & 9,5 & 7.451 & 179 \\
\hline
\end{tabular}

Si hace tan sólo 4 ejercicios presupuestarios, la relación entre los saldos no financieros positivos se situaban (2010) en un porcentaje cercano a la mitad de los saldos no financieros negativos (ratio del 0,54\%). En 2013, esta relación se invierte de manera considerable y pasa a ser del $41,62 \%$, lo que sitúa el impacto de los saldos no financieros negativos en una cifra que no alcanza los 179 millones de euros, frente a los 7.451 millones de euros de aportación positiva.

Esa misma evolución se puede comprobar si se analiza (consultar tabla 17) la evolución de presentaciones realizadas por el subsector local desde el año 2010 y los números y porcentajes de evolución mantenidos por las Corporaciones Locales.

TABLA 17. GRÁFICO SOBRE LA EVOLUCIÓN POR NÚMERO DE CCC.LL. SEGÚN EL SALDO PRESUPUESTARIO NO FINANCIERO (SNF)

Número

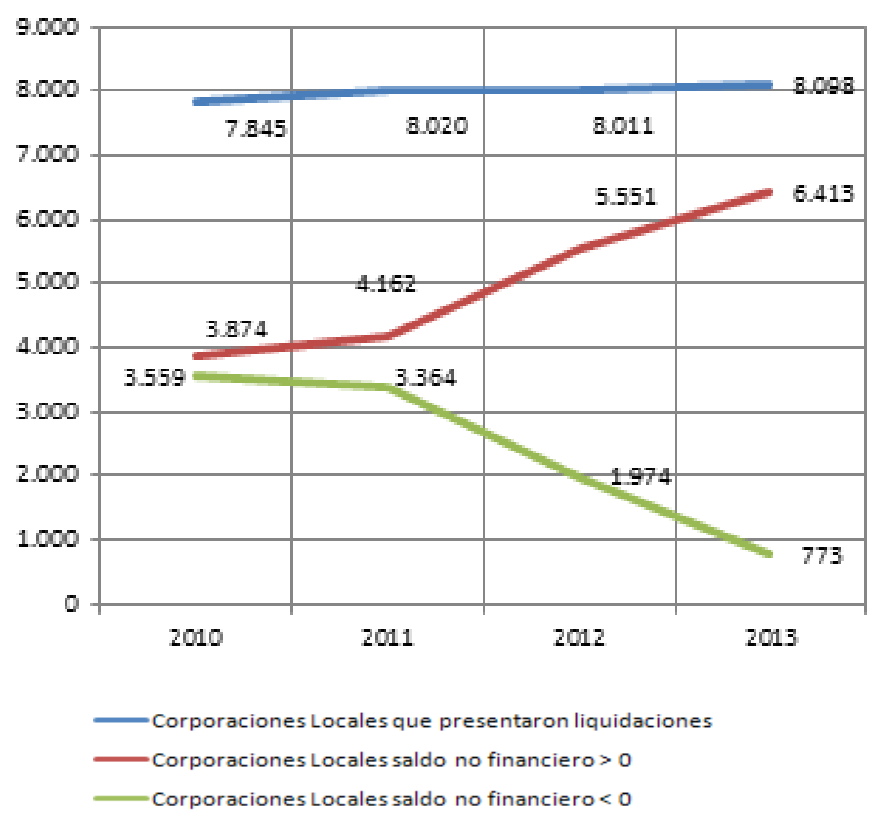

Porcentaje

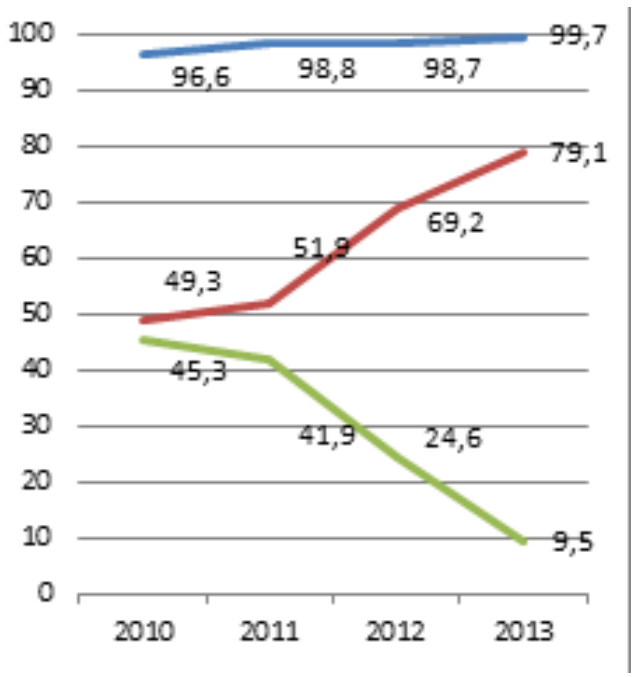

Fuente: elaboración propia a partir de datos del Ministerio de Hacienda y Administraciones Públicas

En conclusión, el conjunto de datos que se facilitan muestran la situación actual de la mayoría de las Entidades Locales en España. Una tendencia coordinada y desarrollada en el marco de la nueva redacción dada al artículo 135 de la Constitución Española. Y que en los objetivos proyectados bajo la Ley Orgánica 2/2012, de 27 de abril, de Estabilidad Presupuestaria y Sostenibilidad Financiera, así como en los resultados obtenidos hasta la fecha, si bien, quedan aún retos pendientes por alcanzar, justifican las modificaciones realizadas en el marco de una reforma 
competencial, que deberán asentarse en el tiempo y complementarse con una necesaria revisión del sistema de financiación.

\section{IV.- CONCLUSIONES}

En el marco del nuevo escenario habilitado tras la reforma del artículo 135 de la Constitución Española, el proceso de transformación de la Administración Local nos ofrece un cambio no sólo estructural. También, añade una novedosa agenda para la gestión económico-financiera de las entidades locales.

Los principios de estabilidad presupuestaria y sostenibilidad financiera desarrollados al amparo de la LOEPSF y la Ley 27/2013, de racionalización y sostenibilidad de la Administración Local conforman un nuevo escenario que adapta la anterior Ley 7/1985, reguladora de las Bases del Régimen Local introduciendo la comprobación y seguimiento de unos determinados indicadores de gestión para todas y cada una de las entidades locales. La relación pasa por la comprobación de la estabilidad presupuestaria, el nivel de endeudamiento, la sostenibilidad financiera, el techo de gasto y los periodos medios legales de pago a proveedores.

Los efectos de la extensión de los mecanismos incorporados al modelo de gestión, no sólo vienen a sobrepasar los tradicionales debates relacionados con modelos centralizados o descentralizados de gasto e ingreso por parte de las haciendas subcentrales.

Dada la urgencia en la que se ve inmersa el conjunto de la Administración española. Y en concreto, la Administración local. La revisión del principio de estabilidad presupuestaria, la inclusión de la consolidación fiscal al máximo rango normativo, así como la adopción de un incesante número de medidas dirigidas a dotar de una mayor liquidez; ayudar a aflorar y transformar la deuda comercial en financiera a través de los planes de pago a proveedores; realizar un continuo seguimiento de la sostenibilidad financiera; incorporar una mayor transparencia; priorizar la garantía del pago de los servicios relacionados con la sociedad del bienestar; e incentivar inversiones proyectadas bajo parámetros de solidez financiera y revisión anual para el conjunto de las entidades locales, vienen a dar una respuesta efectiva cuyo resultado agregado aporta unos números muy positivos para el conjunto de la Administración española.

En tan sólo tres ejercicios presupuestarios, los que van desde los preocupantes resultados obtenidos por las entidades locales en 2011 (-0,39\% del PIB) a los concluyentes del año 2013 (0,52\% del PIB), sitúan al subsector de las corporaciones locales como el único que aporta un resultado positivo a los efectos de cumplimiento del objetivo de déficit del conjunto de las Administraciones españolas. Sin duda, gracias a la Administración local ese compromiso con nuestros socios europeos es una realidad.

No obstante, conviene indicar que ese resultado es consecuencia del desarrollo de un deber coordinado sustentado en los principios de plurianualidad, responsabilidad y lealtad institucional.

El comportamiento de la Administración Local convierte a este subsector en el protagonista de la reforma estructural que incorpora el mencionado artículo 135 de la Constitución Española. Los resultados así lo avalan.

El proceso de coordinación motivada iniciado en el año 2011 debe continuar. Sólo el tiempo dará o quitará razones. A día de hoy, con las matizaciones y actualizaciones necesarias a incorporar, nos presenta un proceso en desarrollo bajo una senda adecuada que aporta estabilidad y viene a garantizar un nivel de servicios mínimos fundamentales al ciudadano.

Finalmente, conviene no obviar, como elemento de cierre al modelo propuesto, el procedimiento de déficit excesivo en el que está inmerso nuestro país y los objetivos que fueron comprometidos ante nuestros socios europeos. La Administración y, en concreto, las entidades locales, vienen a comportarse, en este caso, como un ser vivo en relación con su entorno. Y esto nos depara un horizonte en continuo movimiento con nuevos retos a superar.

\section{BIBLIOGRAFÍA}

Algarra Paredes, A; Romera Jiménez, O. "The challenge of efficiency, control and innovation as driving mechanisms of reforms in public Administration". European Organisation of Supreme Audit Institutions Magazine. No 19. Madrid. 2013. Pages 93-94. ISSN: 1027-8982. Disponible en: http://www.eurosai.org/.content/ documents/magazines/visoresEn/ver19/sources/index.htm?\&lng=en Boletín Estadístico del Personal al Servicio de las Administraciones Públicas, datos a 1 de enero de cada año. Disponible en: http://www.seap.minhap.gob.es/ publicaciones/centro_de_publicaciones_de la_sgt/Periodicas.html 
Cabañes, M.L; Lorca, A. Microeconomía. Thomson Civitas. $3^{\text {a }}$ edición. 2006. Navarra. 84-470-2501-2

Delgado Téllez, M; Hernández de Cos, P; Hurtado, S; Pérez, J. “Los mecanismos extraordinarios de pago a proveedores de las Administraciones Públicas en España. Documentos ocasionales. № 1501 (2015). Madrid. ISSN: 1696-2230 (edición electrónica).

Díaz Lema, J.M. (Coord). "Sostenibilidad financiera y Administración local: un estudio comparado". Tirant lo Blanch. Valencia 2014. ISBN: 978-84-9086-104-2.

Liquidación presupuestaria de las Entidades Locales (1993-2013). Disponible en: http://serviciosweb.meh.es/ apps/EntidadesLocales/

Martín Fernández, J y otros. Aspectos financieros de la reforma local. Ley 27/2013, de 27 de diciembre, de racionalización y sostenibilidad de la Administración Local. Tirant Lo Blanch (2014). Valencia. 978-84-90-53-861-6.

Periodo medio de pago de las Entidades Locales (2014). Disponible en: http://www.minhap.gob.es/es-ES/ Areas\%20Tematicas/Administracion\%20Electronica/OVEELL/Paginas/ConsultaPMPEELL.aspx

Peña Velasco, Gaspar. Deuda pública y ley de presupuestos / Gaspar de la Peña Velasco., en Las Cortes Generales / [organizadas por la] Dirección General del Servicio Jurídico del Estado. Madrid : Instituto de Estudios Fiscales, D.L. 1987. -- Vol. III (p. 1907-1933).

PlanPresupuestario(2015). Disponibleen: http://www.minhap.gob.es/Documentacion/Publico/GabineteMinistro/ Varios/P_PRESUPUESTARIO_2015_ES.pdf

Romera Jiménez, O; Rodríguez Márquez, J. “Un estudio sobre gasto impropio en la Administración Local española”. Doc n³/2014. Revista Documentos. Instituto de Estudios Fiscales. Madrid 2014. 38 páginas. I.S.S.N.: 15780244. NIPO: 634-14-007-8. Disponible en: http://www.ief.es/documentos/recursos/publicaciones/documentos trabajo/2014_03.pdf

Romera Jiménez, O; Rodríguez Márquez, J. Medidas de la Ley de Racionalización y Sostenibilidad de la Administración Local dirigidas a mejorar la eficiencia de la planta municipal española: el nivel óptimo de prestación de los servicios locales". Revista Crónica Presupuestaria. I.S.S.N.: 2340-4868. N.I.P.O.: 634-14-030-5. Disponible en: http://www.ief.es/documentos/recursos/publicaciones/revistas/cronica_presupuestaria/06ROMERA.pdf

\section{Índice legislativo}

Ley Orgánica 2/2012, de 27 de abril, de Estabilidad Presupuestaria y Sostenibilidad Financiera. BOE número 103, de 30 de abril de 2012. (2012). Referencia: BOE-A-2012-5730. Disponible en: https://www.boe.es/diario boe/txt. php?id=BOE-A-2012-5730

Ley Orgánica 9/2013, de 20 de diciembre, de control de la deuda comercial en el sector público. BOE número 305, de 21 de diciembre de 2013 (2013). Referencia: BOE-A-2013-13425. Disponible en: http://www.boe.es/diario boel txt.php?id=BOE-A-2013-13425

Ley 25/2013, de 27 de diciembre, de impulso de la factura electrónica y creación del registro contable de facturas en el Sector Público BOE número 311, de 28 de diciembre de 2013 (2013). Referencia: BOE-A-2013-13722. Disponible en: http://boe.es/boe/dias/2013/12/28/pdfs/BOE-A-2013-13722.pdf

Real Decreto Legislativo 2/2004, de 5 de marzo, por el que se aprueba el texto refundido de la Ley Reguladora de las Haciendas Locales. BOE número. 59, de 09/03/2004 (2004). BOE-A-2004-4214. Disponible en: https://www. boe.es/buscar/act.php?id=BOE-A-2004-4214

Ley 27/2013, de 27 de diciembre, de racionalización y sostenibilidad de la Administración Local. BOE número 312, de 30 de diciembre de 2013. Referencia: BOE-A-2013-13756. Disponible en: https://www.boe.es/diario_boe/txt. php?id=BOE-A-2013-13756

Real Decreto-ley 4/2012, de 24 de febrero, por el que se determinan obligaciones de información y procedimientos necesarios para establecer un mecanismo de financiación para el pago a los proveedores de las entidades locales. BOE número 48, de 25 de febrero de 2012. BOE-A-2012-2722. Disponible en: http://www.boe.es/ boe/dias/2012/02/25/pdfs/BOE-A-2012-2722.pdf

Real Decreto-ley 4/2013, de 22 de febrero, de medidas de apoyo al emprendedor y de estímulo del crecimiento y de la creación de empleo. BOE número 47, de 23 de febrero de 2013. Referencia: BOE-A-2013-2030. Disponible en: http://www.boe.es/boe/dias/2013/02/23/pdfs/BOE-A-2013-2030.pdf 
Real Decreto-ley 8/2013, de 28 de junio, de medidas urgentes contra la morosidad de las administraciones públicas y de apoyo a entidades locales con problemas financieros. BOE número 155, de 29 de junio de 2013. Referencia: BOE-A-2013-7063. Disponible en: http://www.boe.es/boe/dias/2013/06/29/pdfs/BOE-A-2013-7063.pdf

Orden HAP/2105/2012, de 1 de octubre, por la que se desarrollan las obligaciones de suministro de información previstas en la Ley Orgánica 2/2012, de 27 de abril, de Estabilidad Presupuestaria y Sostenibilidad Financiera. BOE número 240, de 5 de octubre de 2012. Referencia: BOE-A-2012-12423. Disponible en: https://www.boe.es/diario boe/txt.php?id=BOE-A-2012-12423

Orden HAP/419/2014, de 14 de marzo, por la que se modifica la Orden EHA/3565/2008, de 3 de diciembre, por la que se aprueba la estructura de los presupuestos de las entidades locales. BOE» número 67, de 19 de marzo de 2014. Referencia: BOE-A-2014-2922. Disponible en: http://www.boe.es/diario_boe/txt.php?id=BOE-A-2014-2922

Orden HAP/2075/2014, de 6 de noviembre, por la que se establecen los criterios de cálculo del coste efectivo de los servicios prestados por las entidades locales. BOE número 270, de 7 de noviembre de 2014. Referencia: BOE-A-2014-11492. Disponible en: https://www.boe.es/diario boe/txt.php?id=BOE-A-2014-11492

Real Decreto-ley 17/2014, de 26 de diciembre, de medidas de sostenibilidad financiera de las comunidades autónomas y entidades locales y otras de carácter económico. BOE número 315, de 30 de diciembre de 2014. BOE-A-2014-13613. Disponible en: http://www.boe.es/boe/dias/2014/12/30/pdfs/BOE-A-2014-13613.pdf

Ley 28/2014, de 27 de noviembre, por la que se modifica la Ley 37/1992, del IVA. Disponible en: http://boe.es/ boe/dias/2014/11/28/pdfs/BOE-A-2014-12329.pdf

Ley de Presupuestos Generales del Estado 2015. Disponible en: http://www.boe.es/diario_boe/txt. php?id=BOE-A-2014-13612

Ley 16/2013, de 29 de octubre, por la que se establecen determinadas medidas en materia de fiscalidad medioambiental y se adoptan otras medidas tributarias y financieras. Disponible en: http://www.boe.es/boe/ dias/2013/10/30/pdfs/BOE-A-2013-11331.pdf

Ley 27/2014, de 27 de noviembre, del Impuesto sobre Sociedades. Disponible en: http://www.boe.es/boe/ dias/2014/11/28/pdfs/BOE-A-2014-12328.pdf

Reforma del artículo 135 de la Constitución Española (2011). Disponible en http://www.congreso.es/consti/ constitucion/indice/sinopsis/sinopsis.jsp?art=135\&tipo=2

Real Decreto Ley 2/2014, de 21 de febrero. Medida revisada y prorrogada en 2015 mediante el RD-I 17/2014, de 26 de diciembre en su disposición adicional novena. Disponible en: http://www.boe.es/diario boe/txt. php?id=BOE-A-2014-1916

Real Decreto 8/2014 de 4 de julio, de aprobación de medidas urgentes para el crecimiento, la competitividad y la eficiencia. Disponible en: http://www.boe.es/diario_boe/txt.php?id=BOE-A-2014-7064 
